\title{
An Implicative Analysis on the Memorability of Functional Forms of Advertisements in Web Media
}

\author{
Dr. K. Pongiannan \\ Assistant Professor \\ PG \& Research Department of Commerce \\ Government Arts College \\ Dharmapuri - 636 705, Tamilnadu, India.
}

\begin{abstract}
The Web has wide applicability in the areas of research, business, communication and several other emerging fields. This has led to the exponential increase in the number of users of Web which enables them to access from anywhere at any time. Hence, the marketers are using the Web as a medium for advertisement to attract this mass audience. The advertisement posted by the marketer in the Web persuades the customer to find comparative information about companies, products, competitors and prices without leaving their place. Also unlike other media, the Web advertisement has a unique advantage of interaction with consumers and can directly lead them to purchase the product. The Web as an advertising media is different from other media for advertisement by two principles. First, the directionality of the advertising message is reversed. Second, Web based advertising works within a different set of constraints, which emphasize content as much as presentation. Because of these unique features, the Web is considered to be a powerful medium for advertisement. Keeping in view of these features of web media, this paper discusses about the impact of the various forms of web advertisements on the level of memorability among the users of web for viewing advertisements.
\end{abstract}

Keywords: Memorability, Media for advertisement, Web advertisements, Advertising message, Functional forms of web advertisements.

\section{INTRODUCTION}

The Web as an advertising media is different from other media for advertisement by two principles. First, the directionality of the advertising message is reversed. In traditional advertising, the message is imposed on the consumer, through mass marketing techniques such as mass media broadcasting of commercials and print advertisements, telemarketing, and mass mailings. But in the Web, the consumer searches for a product advertisement through the Internet. Second, traditional advertising uses brief and distilled messages to catch the consumer's attention and depend on the power of repetition to deliver the message (S.A. Chunawalla and K.C. Sethia, 1997). Content is minimized to fit the time constraints of a television commercial or the size constraints of a magazine page, whereas Web based advertising works within a different set of constraints, which emphasize content as much as presentation. Further, the effectiveness of web advertisement is based upon the reputation of the website containing the advertisement (Shamdasani et al., 2001). Because of these unique features, the
Web is also considered to be a powerful medium for advertisement (Philip Kotler 2000).

\subsection{Functional forms of Web Advertisements}

There are various functional forms of web advertisements which includes Banner, pop-ups, sponsorship, advertorials, interstitials, e-mail advertisements, etc. The Pop-Up form of web advertisement is a small window containing advertisements which appear when accessing a certain Website displayed in the same window. (Brain Marshall, 2002). Banner form of web advertisement is like a billboard that appears across the top or bottom of the Web page and when clicked by the user, it sends him to the advertiser's Website. (S.H.H. Kazmi and Satish K. Batra 2006).

Interstitials, also called as intermercials are the recent form of Web advertisements which appear on the computer screen while waiting for the Website's content to download. The sponsorship form of Web advertising is of two types. The regular sponsorships occur when a company pays to sponsor a section of a Website for advertisements. The content sponsorship not only sponsors for name association but also participates in providing the content itself (George E. Belch and Michael A. Belch, 2001). Advertisements in editorial form that appear to contain objectively-written opinions are known as paid editorial advertisements, or "Advertorials".

\section{METHODOLOGY}

It was decided that a descriptive study using primary data would be appropriate to investigate the objectives. The instrument used to collect the data was a Questionnaire, collected for a period of one year from $1^{\text {st }}$ June 2009 to $31^{\text {st }}$ May 2010.

\subsection{Objectives of the Study}

The following are the objectives of the present study:

- To obtain the respondents' order of preference for Web as a media for viewing advertisements.

- To cross examine the respondents' order of preference and their level of memorability for advertisements in Web media.

- To analyze the respondents' order of preference and their level of memorability for the various websites to view advertisements.

- To rank the various functional forms of Web advertisements based on the viewers' memorability.

- To examine the reasons for the memorability of advertisements in web media among the respondents. 


\subsection{Sampling frame}

The geographical area of Coimbatore city was chosen as the Universe. The main reason for choosing Coimbatore City is that the investigator is located here and is familiar with the place.

\subsection{Sampling Technique}

The Questionnaire was administered in person randomly to a majority of respondents in the study area of Coimbatore City, after oral confirmation that they are actively involved in viewing advertisements while surfing websites. Also, Snowball Sampling Technique was used to select the respondents who are stationed faraway from the researcher. On this basis the questionnaire was administered to 1,300 respondents with a yielding rate of $77.1 \%$ (1001 usable Questionnaires).

\subsection{Techniques used for analysis}

The techniques used for analysis are i) Descriptive statistics such as frequency analysis and cross tabulation ii) Nonparametric tests such as Chi-Square test and Friedman Two-Way ANOVA.

\section{ANALYSIS AND INTERPRETATION}

The data for the present study collected from the respondents through Questionnaire were tabulated and analyzed using appropriate statistical techniques mentioned in the research methodology. The results from the statistical analysis and the objective-wise analysis of the study are presented in this section. All the numerical results of the percentage analysis are rounded off to the first significant digit.

\subsection{Respondents' order of preference for Web as a medium for advertisements}

The respondents' order of preference for Web as a medium for advertisements was analyzed using percentage analysis and ChiSquare test with the following null and alternative hypotheses:

$H_{0}$ : There is no significant difference in the respondents' order of preference for Web as a medium for advertisements.

$H_{1}$ : There is a significant difference in the respondents' order of preference for Web as a medium for advertisements.

Table 1 Respondents' order of preference for Web as a medium for advertisements

\begin{tabular}{|c|c|c|c|c|c|}
\hline $\begin{array}{l}\text { S. } \\
\text { No. }\end{array}$ & $\begin{array}{c}\text { Order of } \\
\text { preference }\end{array}$ & Frequency & Percentage & $\begin{array}{l}\text { Cumulative } \\
\text { Percentage }\end{array}$ & $\begin{array}{l}\text { Chi-Square } \\
\text { (Significance } \\
\text { at } 5 \% \text { Level) }\end{array}$ \\
\hline 1. & First & 186 & 18.6 & 18.6 & \multirow{4}{*}{$\begin{array}{c}433.285 \\
(0.000)\end{array}$} \\
\hline 2. & Second & 644 & 64.3 & 82.9 & \\
\hline 3. & Third & 171 & 17.1 & 100.0 & \\
\hline & Total & 1001 & 100.0 & & \\
\hline
\end{tabular}

Table 1 elucidates that $18.6 \%$ of the respondents have selected Web media as their first preference for advertisements, followed by $64.3 \%$ of them selecting it as their second preference and $17.1 \%$ of them selecting it as their third choice for advertisements. Chi-square statistic (433.285) reveals that the respondents' order of preference for Web as a medium for advertisements differs significantly. Hence, $H_{0}$ is rejected and $H_{l}$ is accepted at 5\% level of significance. Thus, the respondents do not have equal order of preference for Web as a medium for advertisements.

\subsubsection{Respondents order of preference and their level of memorability for advertisements in Web media}

The respondents were surveyed to know about their level of memorability of advertisements viewed in web media. The level of memorability was captured on a three point scale viz., high, medium and low which was cross analyzed with the respondents order of preference for web media and Chi-Square test was performed to test the significance level with the following null and alternative hypotheses:

$H_{0}$ : There is no significant difference in the respondents' order of preference and their level of memorability for advertisements in web media.

$H_{1}$ : There is a significant difference in the respondents' order of preference and their level of memorability for advertisements in web media.

The results are tabulated in Table 2 .

Table 2 Respondents' order of preference and their level of memorability for viewing advertisements in

Web Media

\begin{tabular}{|c|c|c|c|c|c|}
\hline \multicolumn{2}{|c|}{$\begin{array}{c}\text { Web } \\
\text { advertisements }\end{array}$} & \multicolumn{2}{|c|}{ Order of preference } & \multirow{2}{*}{ है } \\
\cline { 2 - 5 } & First & Second & Third & \\
\hline \multirow{2}{*}{} & High & 38 & 126 & 28 & 192 \\
\cline { 2 - 5 } & $\begin{array}{c}\text { Mediu } \\
\mathrm{m}\end{array}$ & 101 & 204 & 44 & 349 \\
\cline { 2 - 5 } & Low & 47 & 314 & 99 & 460 \\
\cline { 2 - 5 } & Total & $\mathbf{1 8 6}$ & $\mathbf{6 4 4}$ & $\mathbf{1 7 1}$ & $\mathbf{1 0 0 1}$ \\
\hline
\end{tabular}

Chi-Square $=50.751 ; p=0.000$ at $5 \%$ level of Significance

Table 2 reveals that 38 respondents who have chosen Web as their first order of preference have high level of memorability for the advertisements viewed in web media. Alternatively, the majority of the respondents who have high memorability for advertisements in web media (126) have preferred Web media as their second choice. On the other hand, 28 respondents who preferred Web media as their third choice also have high level of memorability for web advertisements.

On examination of the respondents who have medium level of memorability for web advertisements, it is evident that majority of them (204) have preferred web media as their second choice. Similarly, 101 respondents have preferred web as their first choice followed by 44 of them as their third choice for viewing advertisements. Both of these groups of respondents have medium level of memorability for web advertisements.

Similarly, 460 respondents have very low level of memorability for advertisements in web media. Among them 47, 314 and 99 respondents have preferred web media as their first, second and third choice of preference for viewing advertisements in web media respectively.

With the cross-examination, the test of significance was performed using Chi-Square test. It is found that Chi-Square 
statistic is 50.751; $\mathrm{p}=0.000$. Hence, $H_{0}$ is rejected and $H_{1}$ is accepted at $5 \%$ level. Thus, it indicates that the difference in the respondents' preference for Web media across their level of memorability for web advertisements is significant.

\subsection{Respondents' order of preference for the various Websites to view advertisements}

The respondents were requested to rank their favourite websites which are most frequently viewed for advertisements. To test for significant difference in the respondents' order of preference for viewing advertisements in various Websites, Chi-Square test was conducted and mean-ranks were obtained using Friedman Two - Way ANOVA. The appropriate null and alternative hypotheses are:

$H_{0}$ : There is no significant difference in the respondents' order of preference for viewing advertisements in various Websites.

$H_{1}$ : There is a significant difference in the respondents' order of preference for viewing advertisements in various Websites.

Table 3 Respondents' order of preference for Websites to view advertisements

\begin{tabular}{|c|c|c|c|}
\hline $\begin{array}{c}\text { S. } \\
\text { No. }\end{array}$ & $\begin{array}{c}\text { Websites for } \\
\text { viewing } \\
\text { advertisements }\end{array}$ & $\begin{array}{c}\text { Mean } \\
\text { Rank } \\
(\mathrm{N}=1001)\end{array}$ & $\begin{array}{l}\text { Chi-Square } \\
\text { (Significance } \\
\text { at } 5 \% \text { Level) }\end{array}$ \\
\hline 1. & Yahoo & 2.42 & \multirow{6}{*}{$\begin{array}{c}1842.312 \\
(0.000)\end{array}$} \\
\hline 2. & Rediff & 2.98 & \\
\hline 3. & Google & 2.73 & \\
\hline 4. & Hotmail & 3.51 & \\
\hline 5. & Indiatimes & 3.79 & \\
\hline 6. & Others & 5.57 & \\
\hline
\end{tabular}

Table 3 shows the results of Friedman Two-Way ANOVA. It is obvious from Chi-Square value $(1842.312 ; \mathrm{p}=0.000)$ that there is a significant difference in the respondents' choice of Websites for viewing advertisements. Hence, $H_{0}$ is rejected and $H_{1}$ is accepted at $5 \%$ level of significance.

On examination of the mean ranks, it is seen that Yahoo is the first preferred Website (mean rank $=2.42$ ) followed by Google (mean rank $=2.73$ ); Rediff (mean rank $=2.98$ ); Hotmail (mean rank $=3.51)$; Indiatimes (mean rank $=3.79)$; and other Websites (mean rank $=5.57$ ) for viewing advertisements.

\subsubsection{Respondents' level of memorability for advertisements in different websites}

The respondents' order of preference for the various websites is cross examined with their level of memorability and the test of significance was performed using Chi-Square test with the following null and alternative hypotheses:

$H_{0}$ : There is no significant difference in the respondents' order of preference and their level of memorability for viewing advertisements in various Websites.

$H_{l}$ : There is a significant difference in the respondents' order of preference and their level of memorability for viewing advertisements in various Websites.
Table 4 Respondents' order of preference and their level of memorability for advertisement in various Websites

\begin{tabular}{|c|c|c|c|c|c|c|c|c|}
\hline \multicolumn{2}{|c|}{ Web Ads } & \multicolumn{7}{|c|}{ Websites } \\
\hline \multirow{5}{*}{ 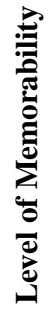 } & & $\begin{array}{l}8 \\
\stackrel{0}{\pi} \\
\text { त्र }\end{array}$ & 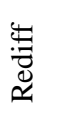 & $\begin{array}{l}\frac{0}{600} \\
8 \\
0 \\
0\end{array}$ & 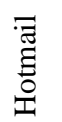 & $\stackrel{\mathscr{\Xi}}{\Xi} \stackrel{\mathscr{d}}{\Xi}$ & $\frac{\mathscr{d}}{\stackrel{ \pm}{0}}$ & 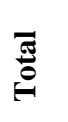 \\
\hline & High & 107 & 61 & 123 & 39 & 15 & 04 & 349 \\
\hline & Medium & 127 & 93 & 183 & 87 & 76 & 20 & 586 \\
\hline & Low & 7 & 11 & 14 & 17 & 4 & 13 & 66 \\
\hline & Total & 241 & 165 & 320 & 143 & 95 & 37 & 1001 \\
\hline
\end{tabular}

Chi-Square $=45.732 ; p=0.000$ at $5 \%$ level of Significance

It is apparent from Table 4 that majority of the respondents (586) have only medium level of memorability for advertisement in their favourite websites. Among them, most of the respondents (183) are users of Google website for advertisements. Similarly, 127 respondents whose favourite website is Yahoo have medium level of memorability. The other websites such as Rediff (93), Hotmail (87), Indiatimes (76) and others (20) have only few favourite respondents with medium level of memorability.

Among the 349 respondents who have high level of memorability, majority of them (123) are users of Google website, followed by Yahoo (107), Rediff (61), Hotmail (39), Indiatimes (15) and other websites (4) for viewing advertisements in web media. Finally, only 66 respondents have low level of memorability after viewing advertisements in their favourite websites.

Further, the Chi-Square statistic $(45.732 ; p=0.000)$ reveals that the respondents differ significantly in their level of memorability after viewing advertisements in their favourite websites. Hence, $H_{0}$ is rejected and $H_{1}$ is accepted at $5 \%$ level of significance.

\subsection{Respondents' order of preference for the different forms of Web advertisements}

The respondents' order of preference for the various forms of Web advertisements such as Banner advertisements, Pop-ups, Interstitial advertisements, Logos and e-mail advertisements were studied and analyzed using percentage analysis, ChiSquare test and Friedman Two-Way ANOVA. The results for each form of Web advertisements are tabulated.

\section{a. Banner advertisements}

To analyze the respondents' order of preference for banner as a form of Web advertisements, percentage analysis was used. The results are tabulated below: 
Table 5 Respondents' order of preference for Banner form of Web advertisements

\begin{tabular}{|c|l|c|c|c|}
\hline $\begin{array}{c}\text { S. } \\
\text { No. }\end{array}$ & Rank & Frequency & Percentage & $\begin{array}{c}\text { Cumulative } \\
\text { percentage }\end{array}$ \\
\hline 1. & First & 319 & 31.9 & 31.9 \\
\hline 2. & Second & 228 & 22.8 & 54.7 \\
\hline 3. & Third & 163 & 16.3 & 71.0 \\
\hline 4. & Fourth & 154 & 15.4 & 85.4 \\
\hline 5. & Fifth & 137 & 13.7 & 100.0 \\
\hline & Total & $\mathbf{1 0 0 1}$ & $\mathbf{1 0 0 . 0}$ & \\
\hline
\end{tabular}

Table 5 shows the percentage analysis of Banner form of Web advertisements. It is evident that, $31.9 \%$ of the respondents have reported first rank; $22.8 \%$ of them have reported second rank; $16.3 \%$ of them have reported third rank; $15.4 \%$ of them have reported fourth rank; $13.7 \%$ of them have reported fifth rank for banner form of Web advertisements. Thus, majority of the respondents $(31.9 \%)$ have preferred banner advertisements in the first place.

\section{b. Pop-Ups}

To examine the respondents' order of preference for pop-ups as a form of Web advertisements, percentage analysis was used. The results are tabulated below:

Table 6 Respondents' order of preference for Pop-up form of Web advertisements

\begin{tabular}{|c|l|c|c|c|}
\hline $\begin{array}{c}\text { S. } \\
\text { No. }\end{array}$ & Rank & Frequency & Percentage & $\begin{array}{c}\text { Cumulative } \\
\text { percentage }\end{array}$ \\
\hline 1. & First & 229 & 22.9 & 22.9 \\
\hline 2. & Second & 314 & 31.4 & 54.3 \\
\hline 3. & Third & 153 & 15.3 & 69.6 \\
\hline 4. & Fourth & 141 & 14.1 & 83.7 \\
\hline 5. & Fifth & 164 & 16.4 & 100 \\
\hline & Total & $\mathbf{1 0 0 1}$ & $\mathbf{1 0 0 . 0}$ & \\
\hline
\end{tabular}

From the Table 6, it is clear that $22.9 \%$ of the respondents have ranked the pop-up form of Web advertisements as first; $31.4 \%$ of them have ranked it as second; $15.3 \%$ of them have ranked it as third; $14.1 \%$ and $16.4 \%$ of the respondents have ranked the pop-up form of Web advertisements as fourth and fifth respectively. Thus, majority of the respondents $(31.4 \%)$ have ranked pop-up form of Web advertisements as second.

\section{c. Interstitial advertisements}

The respondents' order of preference for interstitial form of Web advertisements was analyzed using percentage analysis. The results are tabulated below:

Table 7 Respondents' order of preference for Interstitial form of Web advertisements

\begin{tabular}{|c|l|c|c|c|}
\hline $\begin{array}{c}\text { S. } \\
\text { No. }\end{array}$ & Rank & Frequency & Percentage & $\begin{array}{c}\text { Cumulative } \\
\text { percentage }\end{array}$ \\
\hline 1. & First & 162 & 16.2 & 16.2 \\
\hline 2. & Second & 156 & 15.6 & 31.8 \\
\hline 3. & Third & 138 & 13.8 & 45.6 \\
\hline 4. & Fourth & 229 & 22.9 & 68.5 \\
\hline 5. & Fifth & 316 & 31.6 & 100 \\
\hline & Total & $\mathbf{1 0 0 1}$ & $\mathbf{1 0 0 . 0}$ & \\
\hline
\end{tabular}

Table 7 elucidates that $16.2 \%$ of the respondents have ranked the interstitial form of Web advertisements as first; $15.6 \%$ of them have ranked it as second; $13.8 \%$ of them have ranked it as third; $22.9 \%$ and $31.6 \%$ of the respondents have ranked the interstitial form of Web advertisements as fourth and fifth respectively. Thus, majority of the respondents $(31.6 \%)$ have ranked the interstitial form of Web advertisements as fifth.

\section{d. Logos}

The respondents' order of preference for logos form of Web advertisements was analyzed using percentage analysis. The results are tabulated below:

Table 8 Respondents' order of preference for Logos form of Web advertisements

\begin{tabular}{|c|l|c|c|c|}
\hline $\begin{array}{c}\text { S. } \\
\text { No. }\end{array}$ & Rank & Frequency & Percentage & $\begin{array}{c}\text { Cumulative } \\
\text { percentage }\end{array}$ \\
\hline 1. & First & 153 & 15.3 & 15.3 \\
\hline 2. & Second & 140 & 14.0 & 29.3 \\
\hline 3. & Third & 317 & 31.7 & 61.0 \\
\hline 4. & Fourth & 162 & 16.2 & 77.2 \\
\hline 5. & Fifth & 229 & 22.9 & 100 \\
\hline & Total & $\mathbf{1 0 0 1}$ & $\mathbf{1 0 0 . 0}$ & \\
\hline
\end{tabular}

From the Table 8 , it is found that $15.3 \%$ of the respondents have ranked the logos form of Web advertisement as first; $14.0 \%$ of them have ranked it as second; $31.7 \%$ of them have ranked it as third; $16.2 \%$ and $22.9 \%$ of the respondents have ranked the logos form of Web advertisements as fourth and fifth respectively. Thus, majority of the respondents (31.7\%) have ranked logos form of Web advertisements as third.

\section{e. e-Mail advertisements}

The respondents' order of preference for e-mail form of Web advertisements was analyzed using percentage analysis. The results are tabulated below:

Table 9 Respondents' order of preference for E-mail advertisements

\begin{tabular}{|c|l|c|c|c|}
\hline $\begin{array}{c}\text { S. } \\
\text { No }\end{array}$ & $\begin{array}{c}\text { Order of } \\
\text { Preference }\end{array}$ & Frequency & Percentage & $\begin{array}{c}\text { Cumulative } \\
\text { percentage }\end{array}$ \\
\hline 1. & First & 138 & 13.8 & 13.8 \\
\hline 2. & Second & 163 & 16.3 & 30.1 \\
\hline 3. & Third & 228 & 22.8 & 52.9 \\
\hline 4. & Fourth & 317 & 31.7 & 84.6 \\
\hline 5. & Fifth & 155 & 15.5 & 100 \\
\hline & Total & $\mathbf{1 0 0 1}$ & $\mathbf{1 0 0 . 0}$ & \\
\hline
\end{tabular}

Table 9 depicts that $13.8 \%$ of the respondents have ranked the email form of Web advertisements as first; $16.3 \%$ of them have ranked it as second; $22.8 \%$ of them have ranked it as third; $31.7 \%$ and $15.5 \%$ of the respondents have ranked the e-mail form of Web advertisements as fourth and fifth respectively. Thus, majority of the respondents $(31.7 \%)$ have ranked the email form of Web advertisements as fourth. 


\subsubsection{Respondents level of memorability for different forms of web advertisements}

The respondents' level of memorability for the different functional forms of web advertisements were tabulated and test of significance was performed using Chi-Square test with the following null and alternative hypotheses:

$H_{0}$ : There is no significant difference in the respondents' order of preference and their level of memorability for the advertisements in the various functional forms of Web advertisements

$H_{1}$ : There is a significant difference in the respondents' order of preference and their level of memorability for the advertisements in the various functional forms of Web advertisements

Table 10 Respondents' order of preference and their level of memorability for the various functional forms of

Web advertisements

\begin{tabular}{|c|c|c|c|c|c|c|c|}
\hline \multicolumn{2}{|c|}{ Web Ads } & \multicolumn{5}{|c|}{ Forms of Web advertisements } & \multirow[b]{2}{*}{ సี } \\
\hline \multirow{5}{*}{ 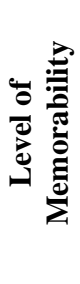 } & & 离 & $\stackrel{\dot{a}}{a}$ & . & $\begin{array}{l}0 \\
\stackrel{0}{0} \\
0 \\
0 \\
0\end{array}$ & $\sum_{j}^{\bar{\pi}}$ & \\
\hline & High & 201 & 174 & 73 & 17 & 10 & 475 \\
\hline & Medium & 215 & 58 & 173 & 9 & 7 & 462 \\
\hline & Low & 14 & 12 & 9 & 16 & 13 & 64 \\
\hline & Total & 430 & 244 & 255 & 42 & 30 & 1001 \\
\hline
\end{tabular}

Chi-Square $=57.279 ; p=0.000$ at 5\% level of Significance

It is apparent from Table 10 that majority of the respondents (475) have high level of memorability followed by 462 respondents have medium level of memorability and 64 respondents with low level of memorability for the various functional forms of web advertisements. Among the 475 respondents, majority of them (201) prefer banner form of web advertisements for high memorability followed by 174 respondents preferring pop-ups, 73 respondents for interstitial, 17 respondents for logos and only 10 respondents for e-mail form of web advertisements.

On the other hand, among the 462 respondents with medium level of memorability majority of them (215) again have preferred banner form of advertisements followed by 173 respondents for interstitials, 58 for pop-ups, 9 for logos and 7 for e-mail form of web advertisements. Thus, it is very clear from the respondents with high level of memorability and medium level of memorability that banner is the most attractive form web advertisements. However, 64 respondents have only low level of memorability irrespective of the various forms of web advertisements.

Further, it is obvious from Chi-Square value $(57.279 ; \mathrm{p}=0.000)$ that there is a significant difference in the respondents' order of preference and their level of memorability for the different forms of web advertisements. Hence, $H_{0}$ is rejected and $H_{1}$ is accepted at $5 \%$ level of significance.

\subsection{Respondents' preference on the reasons for memorability of Web advertisements}

Finally, the reasons for respondents' memorability of advertisements in Web were analyzed and tabulated. The null and alternative hypotheses for the test of significance are:

$H_{0}$ : There is no significant difference in the respondents' preference on the reasons for memorability of Web advertisements.

$H_{1}$ : There is a significant difference in the respondents' preference on the reasons for memorability of Web advertisements.

Table 11 Reasons for the respondents' memorability of Web advertisements

\begin{tabular}{|c|l|c|c|c|}
\hline $\begin{array}{c}\text { S. } \\
\text { No. }\end{array}$ & Reasons & Frequency & Percentage & $\begin{array}{c}\text { Cumulative } \\
\text { Percentage }\end{array}$ \\
\hline 1. & $\begin{array}{l}\text { Multimedia } \\
\text { content }\end{array}$ & 130 & 13.0 & 13.0 \\
\hline 2. & $\begin{array}{l}\text { Real time } \\
\text { interactions }\end{array}$ & 727 & 72.6 & 85.6 \\
\hline 3. & $\begin{array}{l}\text { Easy } \\
\text { accessibility }\end{array}$ & 110 & 11.0 & 96.6 \\
\hline 4. & $\begin{array}{l}\text { Other } \\
\text { reasons }\end{array}$ & 34 & 3.4 & 100.0 \\
\hline & Total & $\mathbf{1 0 0 1}$ & $\mathbf{1 0 0 . 0}$ & \\
\hline
\end{tabular}

Chi-Square $=1231.507 ; p=0.000$ at $5 \%$ level of Significance

Table 11 illustrates that $13 \%$ of the respondents have stated the use of multimedia content is the reason for memorability of Web advertisements; majority of them $(72.6 \%)$ have reported that it is because of real time interactions; $11 \%$ of them have stated that it is because of easy accessibility and $3.4 \%$ of them confirm that it is because of other reasons. Chi-square $(1231.507 ; \mathrm{p}=0.000)$ result depicts that there is a significant difference in the reasons for memorability of Web advertisements. Hence, $H_{0}$ is rejected and $H_{1}$ is accepted at $5 \%$ level of significance.

\section{IMPLICATIONS}

The implications based on the major findings of the study are:

$>$ Since majority of the respondents have preferred banner form web advertisements for their high level of memorability, it is strongly recommended that the advertisements should be hosted in the website in banner form.

$>$ The taste and preferences of the Web users are not constant. Hence, it is suggested that the advertisement for the same product should come in different forms such as Banner advertisements, Pop Ups, Logos or Interstitials at frequent intervals.

$>$ The Web owners host more number of advertisements in a Website which is mostly visited by the users. Consequently, the respondents consider these advertisements especially popups as irritation while accessing other useful information. Hence, it is suggested that such annoyance should be avoided and real time interaction should be enabled in web advertisement. 
It was found that like Television, the Web media also should repeat the same advertisement in the same website to increase its memorability.

It is strongly recommended that the ethical values and code of conduct for advertisements such as avoiding vulgarity, preventing acts of violence and use of decent dress code for models should be strictly adhered in Web media. This avoids the unwanted disturbances and increases the memorability for such advertisements.

\section{CONCLUSION}

The new millennium emerged with revolutionary advances in technology which led to the dynamic growth in the use of Web for entertainment and interaction. Although the Web is highly popular for accessing information through e-mail and browsing, it is not much admired for advertisements. Moreover, the respondents suggest that the standard of advertisements in Web media should be improved. On the other hand, the success of any advertisement lies in its ability to be remembered contributing for memorability and high retention value. Any advertisement with high level of memorability will definitely induce the consumers to go for the product and hence influences their purchase decisions. Hence, this research with implications for advertisements with high level of memorability in web media will help the advertisers, media owners and marketers to develop their advertising strategies in Electronic Media WWW.

\section{REFERENCES}

[1] Chunawalla. S. A, Sethia.K.C. (1997), Fundamentals of Advertising, Theory and Practice, Himalaya Publishing House, Mumbai. pg.1; 218-219.

[2] George E. Belch and Michael A. Belch, (2001), Advertising and Promotion, Tata Mc Graw Hill, New Delhi. pg. 114$115 ; 355-357 ; 495 ; 506-507 ; 516-517$.

[3] Phillip Kotler and Gary Armstrong (2000), Principles of Marketing, Prentice Hall of India, New Delhi. pg.450.

[4] Shamdasani. P.N., Stanaland. A.J.S., Tan. J. (2001), Location: Insights for Advertising Placement on the Web, Journal of Advertising Research. pg. 7-19.

[5] S.H.H. Kazmi and Satish K. Batra, (2006), Advertising and Sales Promotion, Excel Books, New Delhi. pg. 13-18; 280$281 ; 287-288 ; 326-327$

[6] Web advertising article by Brain Marshal 2002 available at http://computer.howstuffworks.com. 